\title{
THE FUTURE OF SOCIAL WORK IN CHILD WELFARE
}

\author{
Jacquelyn McCroskey
}

\begin{abstract}
Child welfare has always been a volatile and dynamic feld of social work practice where policy and practice are continually shaped by attitudes, perceptions and expectations. New developments likely to shift the current ballance in the field of child welfare over the next guarter century include: focus on results and performance measures, focus on child and family well-being, and increasing attention to evidence-based practice.
\end{abstract}

Keywords: child toelfare, outcomes, evidence-based practice, future

\section{INTRODUCTION}

Child welfare has always been a controversial and unsettling field of practice. Focusing on child abuse and neglect is bound to be unsettling, raising highly emotional issues that challenge everyone involved because we all have vivid memories of our own childhoods and strong feelings about what is best for other people's children. Controversy on almost every aspect of policy and practice has been the norm ever since late $19^{\text {th }}$ and early $20^{\text {th }}$ century social workers established the key institutions designed to help and support families. Indeed, the different values and assumptions embodied in the Charity Organization Societies (COS), settlement houses and Societies for the Prevention of Cruelty to Children (SPCC) are still very much in evidence today (Halpern, 1999; Walkowitz, 1999; McCroskey, 2003a).

Social casework methods pioneered by Mary Richmond and other leaders of the COS movement have evolved over time, but they still include investigation, diagnosis, counseling, home visiting and advice for poor, often immigrant, families provided by mostly middle class social workers who may or may not have much experience with child-rearing. Settlement work still focuses on community building, bringing early childhood education, after-school programs, employment opportunities and social activities into poor communities to help families cope in the face of inadequate child care and schools, limited recreational opportunities and the many other devastating correlates of urban poverty. Although the SPCC no longer exists per se, its influence is still felt in both child welfare and law enforcement circles, since SPCC agents were the first protective services workers to police renement houses, "breaking up families of bad character," rescuing their children, and "becoming the feeders of institutions, both reformatory and charitable" (Folks, 1902, p.176).

Each of these three strands of thoughr - social casework, communiry building and child protection - has influenced child welfare policy, practice, training, and research in different ways over the 125 year span of child welfare practice in the United States. Many pcople in the field use the metaphor of the "pendulum swinging back and forth"-between prevention and remediation, helping families and saving children from bad parents,

Jacquelyn McCroskey is John Miner Professor of Child Welfare at the School of Social Work, University of Southern California, Los Angeles, CA 90089-0411.

Copyright (을 2005 Adumees in Social Work Vol. 6 No. 1 (Spring 2005), 156-166 
community supports and enforcement strategies-to capture the experience of working in this volatile field. While there is no reason to believe that these essential tensions will be resolved during the foreseable future, it is very likely that new developments will shift the balance once again over the next quarter century. New developments most likely to cause swings in the child welfare pendulum include:

1. Focus on results and performance measures

2. Focus on child and family well-being

3. Evidence-based practice

\section{FOCUS ON RESULTS AND PERFORMANCE MEASURES}

Although we sometimes speak of "the child welfare system" as if there was a single system that provides child protection, foster care, adoption and family-centered services in the U.S., actually there are approximately 2610 public child protective services agencies employing an estimated 42,600 caseworkers in state, county and ciry jurisdictions throughout the country (U. S. Department of Health and Human Services, 2003). All of these agencies are guided by Federal policy, but there is so much latirude for state and local decision-making that they function quite differenty in most regards.

Federal support for Statewide Automated Child Welfare Information Systems (SACWIS) was firs made available in 1993, and most states now have a functioning SACWIS case management system that regularly reports data to two national data systems-the National Child Abuse and Neglect Data System (NCANDS) and the Adoption and Foster Care Reporting System (AFCARS). State by state comparison data are available from these and other sources [1], but most researchers in the field recognize the profound limitations of existing data sets. In addition to the usual limitations of auromated information systems that depend on busy professionals for accurate and timely input, the states have defined basic ternus differently and comparisons across jurisdictions are sometimes inherently flawed. For example, some jurisdictions have umbrella agencies that include juvenile justice and mental health along with child abuse and neglect functions, while others have separate agencies for each population. Thus, basic data on children in out-of-home care reported by some states have included all three populations, while others have reported only those children removed from their homes due to maltreatment.

The Child and Family Services Review (CFSR) process is a "comprehensive monitoring review system designed to assist States in improving outcomes for children and families who come into contact with the nation's public child welfare systems" (U.S. Department of Health and Human Services, 2005). This federal process, which has been underway for several years now, requires states to assess their own operations, undergo federal sitc reviews, and develop specific Program Improvement Plans (PIP) based on seven outcome areas and systemic factors. Taken together, these outcomes and systems factors now effectively define performance expectations for all child welfare jurisdictions across the country. The CFSR thus adds considerable specificity to the three key goals of safety, permanence and child well-being laid out for child welfare services in the 1997 Adoption and Safe Families Act. The ourcome areas and systemic factors defined in the CFSR are:

Safety Outcome 1 . Children are first and foremost protected from abuse and neglect 
Safety Outcome 2.

Children are safely maintained in their homes when possible

Permanency Outcome 1. Children have permanency and stability in their living situations

Permanency Outcome 2. The continuity of family relationships and connections is preserved

Well Being Outcome 1. Families have enhanced capacity to provide for children's needs

Well Being Outcome 2. Children receive services to meer their educational needs

Well Being Outcome 3. Children receive services to meet their physical and mental health needs

The systemic factors pertain to the following: (1) the Statewide information system; (2) the case review system; (3) training for child welfare staff, foster parents, and adoptive parents; (4) the quality assurance system; (5) the service array; (6) the responsiveness of the agency to the community; and (7) the licensing, recruitment, and retention of foster and adoptive parents. (www.acf.hhs.gov/programs/cb/cwrp/results/statefindings/genfinding04/intro.htm).

The importance of having both clearer definitions of desired results and a process for monitoring performance across the $2600+$ public agencies mandated to serve children and families in this complex and controversial arena cannot be overstared. Focus on results and performance measures may become even more important during the next few years if some of the large-scale changes now under discussion at Federal and Stare levels are enacted. Suggestions have included everything from repealing mandatory reporting laws, separating investigation from service delivery functions, to developing a block grant system (rather than an entitlement) based on key findings from experimentation by states that have Title IV-E waivers (McCroskey 2003a). Clearly, change is in the air around the child welfare system, and having more standardized continuous data on program results will be essential.

Even during the initial rounds, state and local policy makers and administrators have gotten much clearer about where their agencies stand in comparison to others, where improvements are most needed, and where they should focus their efforts in order to meet basic standards. Supervisors and case workers are not only learning abour the practice expectations included in their state's PIP, but realizing the importance of accurate reporting and the uses of SACWIS data for program planning, development and improvement. Many local agencies have begun to see these data as critical resources that could guide and support program planning and improvement, not simply as something required by other levels of government for reimbursement purposes.

States like California with state-administered, county-run systems have set similar statelevel processes in motion to assure that each county's contribution to statewide progress is measured regularly (Needell \& Patterson, 2004). This on-going process requires each of the 58 California counties to carefully align their state-required Self Improvement Plan (SIP) with Californiàs overall plan. In addition to processes mandated at Federal and State levels, some cities and counties are also developing related processes based on the demonstrated value of data-driven planning, performance measurement, and results-based budgeting (Friedman, 1997; Osboume \& Plastrik, 1997; Hogan 1999; McCroskey 2003b), 
and many local jurisdictions are faced with the challenges of coordinating requirements from multiple levels of government. For example the author is working with the Los Angeles County Department of Children and Family Services to align data requirements from the Federal PIP, the State SIP and the County's performance measurement system so that the data inform planning and service improvement without overwhelming caseworkers with more paperwork and reporting requirements, or conflicting with established SACWIS requirements.

Increasing attention to the core data elements included in the CFSR over time should not only improve the validity and reliability of available data, but should increase interest in the potential of data, evaluation and research to improve child welfare services. If accurate, reliable data are not primarily the concern of a small group of child welfare researchers, but a priority for policy makers, agency directors and administrators, the field should see significant improvements in information systems, greater availability of and access to data, and more attention to analyzing these complex data sers. Child welfare has a long way to go, but the fact that policy makers and administrators must now balance attention to the politics of a controversial feld with focus on performance measures and results is an important step forward.

As leaders of child welfare agencies across the country take a more proacrive stance, there should also be increasing attention to the many gaps in current knowledge, encouraging leaders in practice and research to work together to develop shared research agendas. Research partnerships between universitics and public child welfare agencies are well established in some localities [2], but many local agencies, even those in the largest urban areas with the most complex data needs, have nor yet formally established such working partnerships. The work of establishing and supporting such university-agency partnerships in states throughout the country has recently begun under the leadership of Fostering Results and the Children and Family Research Center at the School of Social Work, University of Illinois at Urbana-Champaign [3.] These partnerships should also provide significant opportunities for improving both university-based professional education and scholarship in child welfare.

\section{FOCUS ON CHILD AND FAMILY WELL-BEING}

Because safery and permanence are clearly essential goals for child protection, much of the initial work on measurement issues has focused on indicators in these two areas. There has been less attention thus far to developing measures reffecting child or family well-being beyond initial measures such as providing services to meet educational, health and mental health needs. In 2000 an advocacy group in Los Angeles noted that:

Efforts to measure child well-being are hampered by the lack of appropriate data on meaningful indicators. It is possible to say, however, that, lacking access to or support for adequate health care, appropriate child care and/or effective education or vocational trainm ing, far too many families, particularly families of color, have slipped farther and farther behind economically. The desperation of poverty has driven a disproportionate number to self medication that has deteriorated into substance abuse, further diminishing the families' capacity to meet their children's needs. It is a downward spiral that our lack of will and concerted attention has failed to arrest (Lewis et al, 2000, p. 1). 
Well-being is an extremely important area for further exploration for two reasons: 1) we know that maltreatment affects child development, but have not as yet fully incorporated this knowledge into practice; and 2) we know that families involved with the child welfare system usually live in poor communities that do not have many suppors for families, and that many of these families have a very broad range of service needs, but few localities have successfully integrated or aligned the supports and services needed by these children and their families.

Impacts of maltreatment on child development. In 2000 when the National Research Council and Institure of Medicine reviewed and summarized the research to date in the science of early childhood development, they noted that:

In sum, the neuroscientific research on carly brain development says that young children warranting the greatest concern are those growing up in environments, starting before birth, that fall to provide them with adequate nutrition and other growth-fostering inpurs, expose them to biological insults, and subject them to abusive and neglectful care. (National Research Council \& Institute of Medicine, 2000, p. 217).

Although this finding is certainly not surprising to experienced caseworkers, the "explosion" of research in the neurobiological, behavioral and social sciences has also led to more nuanced understanding of the interactions between genetics and environment in early childhood. For example, children with prenatal exposure to alcohol may have problems with attention and memory, show poor motor coordination, and have difficulty tuning out excess sensory stimuli (p. 201). Children of depressed mothers also face greater risks including difficulties in school, trouble with peer relationships, heightened aggression and impaired self-control (p. 251). Animal experiments suggest that babies with highly dysfunctional parents may have both short and long-term problems in self-regulation. When stress is overwhelming, the organism must attend to immediate challenges as described by the National Research Council and Institute of Medicine (2000):

When threats begin to overwhelm one's immediate resources to manage them, a cascade of neurological changes that begin in the brain temporarily purs on hold the changes in the body that can be thoughr of as furure-oriented: finding, digesting, and storing food; fighting off colds and viruses; learning things that don't matter right now but may be important some time in the future... (p. 212).

The only peer-reviewed scientific study thus far that has included images comparing the brains of maltreated children with those of non-maltreated children matched for age and sex showed smaller brain volumes and other physiological differences in the brains of maltreated children. These differences were correlated with the duration of trauma, with children who had been abused longer exhibiting grearer damage (National Resentch Council and Institure of Medicine, 2000, p. 257).

Another set of findings which provide important insighrs both for social workers, and for the relarives, foster and adoptive parents who may assume care for these children, focus on the behaviors and internal models that young children may develop as a result of adverse, disorganized or disrupted parenting. Research shows that 70 to $100 \%$ of maltreated infants exhibir insecure attachment, and furthermore that the parterns of insecure attachment they exhibit are often atypical. Maltreated infants may "inconsistently employ avoidant 
and resistant attachment straregies" or exhibit "[b]izarre behaviors, including interrupted movements and expressions, freezing, stilling, and apprehension" (Cicchetti, Toth \& Rogosch, 2000, p. 400). Difficulties related to insecure attachment may continue to ripple through later development and "interventions to alter the working models of maltreated children are essential in order to redirect maltreated children on a trajectory toward psychological wellness" (Ciccherti, Toth \& Rogosch, 2000, p. 401). Unfortunately very few of the maltreated children known to the child welfare system receive the kinds of treatment they need to develop new mental models of trusting reciprocal human relationships.

A number of authors who have reviewed this literature (National Research Council \& Institute of Medicine 2000; Trickett \& Schellenbach,1998; Wolfe,1999), conclude that there is reason to believe that natural resilience protects many maltreated children from permanent harm, especially when they are able to develop secure attachments with other caregivers. Even children who have missed key developmental opportunities due to inattentive, disorganized or disrupted parenting can, with loving attention and care, make up for lost time.

But how many of the social workers, foster parents, relatives, guardians and adoptive parents involved in the child welfare system understand the specific physiological and behavioral consequences of abuse and neglect for the children in their care? And how well is the child welfare system preparing them to provide the care needed by children at different developmental stages, with different familial experiences including intensities and durations of abuse? The answer is that we probably are nor doing a very good job now, except in some special programs. Hopefully, further development of this research arena will encourage agencies that have focused primarily on child protection to expand their programs in order to include more attention to multidisciplinary treatment programs and family-centered services. Training and support for caregivers is also essential, so they know what to expect from the children they are responsible for and the children stand a better chance of finding the loving attention and care they need.

\section{Service integration and alignment}

The challenges of integrating services for children and families have been discussed from many perspectives (Austin 1997; Schorr 1997; Brabeck, Walsh \& Latta 2003), but most authors agree that, while challenging, it is possible to work through the barriers of service fragmentation, siloed funding streams, and incompatible organizational cultures in order to better serve vulnerable children and families. Work being done in the Harlem Children's Zone (Tough, 2004), the Atlanta Project (Cutler, 1997) and in Los Angeles County by the Children's Planning Council (McCroskey, 2003b) provide examples of the broad-based prevention-oriented partnerships that are possible, in even the biggest and most complex urban areas.

Given the multifaceted needs of families involved in the child welfare system, and the difficulties of negotiating complex human services systems, some child welfare agencies have devoted considerable attention in recent years to developing community partnerships for protecting children (Zimmerman 2003). Clearly, families who are known to the child welfare system at almost any point - families who are reported for suspected abuse, 
those who receive voluntary services while keeping their children at home, those who are reunified with their children after foster care, or relatives, guardians and adoptive parents seeking to create new families for these children - have additional needs for support and services that child welfare does not control directly. These include child care, housing, employment, substance abuse treatment, health and mental health services, among others.

One essential element of an effective community parnership for child protection is the agency's capacity to support differential or alternative response strategies. These strategies, described by Waldfogel as core to a new paradigm for breaking the cycle of abuse and neglect place:

...greater emphasis on how CPS identifies the families to be served by cach
part of the child protective services system and how it develops case-specific
assessments and service plans, in order to deliver a customized response...
[this new paradigm] calls for a community-based system, in which CPS
continues to play the lead role but works with the criminal justice system
and with other public and private agencies to provide preventive and pro-
tective services for the full range of children in need of protection (Waldfo-
gel, 1998, p. 138).

Work to date in communities around the country suggests that community partnerships aligning child welfare with a broad range of other organizations providing essential services to families and children offer considerable promise for the furure. Potential partners include public agencies providing early childhood and $\mathrm{K}-12$ education, health and mental health care, substance abuse treatment and income support services; private not-for-profit service providers; grassroots and community based organizations; as well as civic and faith-based groups concerned about families. Creating and supporting such partnerships seems to be a promising approach (McCroskey, in press), augmenting the focus of protective services on safety and permanence with a third focus on well-being that can help to create a shared agenda among a broad range of community partners.

\section{EVIDENCE-BASED PRACTICE}

The evidence base to support current child welfare practice is fragmentary at best and irresponsible at worst (Epstein, 1999). Thus, efforts to summarize and evaluate the existing evidence in relationship to specific aspects of practice have been particularly welcome (Cohen, Berliner \& Mannarino, 2000; Comer \& Frazer; 1998; Davies, Nutley \& Smith 2000; Kluget, Alexander \& Curtis, 200; Layzer \& Goodson, 2001; Marsenich, 2002; McAuley, Pecora \& Rose, in press; Thomas et al, 2002).

Finding evidence to support effective practice strategies that address the disproportionate number of children of color in the child welfare system is a very high priority topic for further investigation. Depending on the jurisdiction, children of color in different age groupings are not only referred at higher rates, they are also more likely to be placed in out-of-home care, to remain in foster care for longer periods of times and less likely to be adopted (Geen, 2003). For example in Los Angeles, foster care rates for different racial/ethnic groups differ dramatically. In 2003, African American children were most likely to be placed in foster care with a rate of 49.2 per 1000 children under 18 , followed by American Indian children at 20.2. Latino and White children had roughly equivalent 
rates of 8.2 and 8.3, while Asian Pacific Islander children were least likely to be in foster care at a rate of 2.1 (Los Angeles County Children's Planning Council 2004).

These racial and ethnic group differences also seem to interact with demographic and community factors in ways that are little understood at present. For example, in 2002 the South region of LA County with the highest number of child abuse and neglect referrals $(27,283)$, also had the highest percentage of children living in poverty $(34 \%)$, the lowest percentage of third grade public school students reading at or above national averages $(22 \%)$, and the lowest percentage of high school graduates (66\%) [4]. Further investigation of the interactions among such variables is much needed in localities throughour the country.

One promising approach that may help the child welfare field to develop a more substancial evidence base is the widespread use of structured assessment instruments and processes to support decision-making about risk and safety. Although people may overestimate the accuracy of such structured protocols (Munro 2004), they nonetheless offer continuing sources of practical information to support training, supervision and administrative decision-making.

Hopefully, such tenrative steps towards evidence-based practice in the child welfare system will provide practical information that is actually used by administrators and caseworkers, reinforcing the need for a deeper and more far-reaching research base to support practice in the field. If so, university-agency partnerships may be used to good effect, improving practice and expanding the knowledge base in a very complex, emotional and political arena of social work practice. Given the sheer number of local child welfare jurisdictions, and the very different demographics, characteristics and political prioritics of the communities they serve, these partnerships should be able to explore a broad range of research questions, investing both in rigorous interdisciplinary methodologies and in participative evaluation strategies that can help give voice to vulnerable children and their families. If so, social workers entering the field in the next quarter century will be much betrer informed than their predecessors, and the field as a whole should be more successful in improving outcomes for children and families.

\section{Notes}

1. Sources for comparative data include: 1) NCANDS, National Child Abuse and Neglect Data Systen (ndacan.cornell,edu); 2) AFCARS, Adoption and Foster Care Reporting System, AFCARS (wwwacf.his.gov/programs/cb/dis/afcars/publications/afcars.hrm); 3) NDAS, the National Data Analysis System run by the Child Welfare League of America (ndas.cwla.org. Data comparing counties is also available from sites such as the University of California Berkeley's Center for Social Service Research, Child Welfare Rescarch Center (www.cssr.berkeley.edu/childwelfare).

2. For example, the Children and Family Research Center ac the School of Social Work, University of Illinois at Urbana-Champaign began their partnership with the Illinois State Department of Children and Family Services in 1996 .

3. In 2003 The Pew Charitable Trusts initiated support for the Children and Family Research Center at the School of Social Work, University of Ullinois at Urbana-Champaign to launch a public education and outreach campaign called Fostering Results. The campaign works nationally and 
in selected states to engage infuential leaders, using media, reports and meetings around key issues. (www. fosteringresults.org)

4. Los Angeles County uses eighr geographic regions, or Service Planning Ateas (SPAs), to organize and facilitate coordinated planning and information sharing. See the website of the Children's Planning Council for more detail on the SPAs, and for recent data by SPA and by zip code included in the 2004 Children's Scorecard (www childrensplanningcouncil. org).

\section{References}

Austin, M. J. (ed.). (1997). Human sarvices integration. NY: The Haworth Press.

Brabeck, M. M., Walsh, M. E. \& Larra, R. E. (eds.). Meeting at the byphen: Schools-universities-communities-professions in collaboration for student achievement and well-being. $102^{\text {nd }}$ yearbook of the National Society for the Study of Education. Chicago, IL: University of Chicago Press.

Cicchetti, D., Toth, S. L. \& Rogosch, F. A. (2000). The development of psychological wellness in maltreated children. In D. Cicchetri, J. Rappaport, I. Sandler \& R. P. Weissberg (eds.). The promotion of uellness in children and adolescents. Washington DC: Child Welfare League of American Press.

Cohen, J. A., Berliner, L. \& Mannarino, A. P. (2000). Treating traumatized children, A research review and synthesis. Tramma, violence and abuse, 1 (1): 29-43.

Comer, E. W. \& Frazer, M. W. (1998). Evaluation of six family support programs:Are

they effective? Families in society: The journal of contemporary haman services, 79(2):

$134-148$.

Cutler, 1. (1997). Leaming together: Reflections on the Atlantu Project. Atlanta, GA: The America Project.

Davies, H. T. O., Nutley, S. M. \& Smith, D. C. (eds.). (2000). What works? Evidence-based policy and practice in public services. Bristol, UK: The Policy Press.

Epstein, W. M. (1999). Children who conld bave been. The legay of child welfare in wealthy America. Madison, WI: University of Wisconsin Press.

Folks, H. (1902). The care of destitute neglected and delingutent children. (Classics sertes). Washington DC: National Association of Social Workers.

Friedman, M. (1997). A guide to developing and using performance measures in results-based budgeting. Washington DC: The Finance Project. (See also www.resultsaccountability.com)

Geen, R. (2003). Who will adopt the foster care children left behind? Washington DC: Urban Institute. (http://www.urban.org/url,cfm?ID=310809)

Hogan, C. D. (1999). Vermont communities count, Using results to strengthen services for familites and children. Baltimore, MD: Annie E. Casey Foundation.

Halpern, R. (1999). Fragile families, fragile solutions: A bistory of supportive services for families in poverty. New York: Columbia University Press.

Kluger, M. P., Alexander, G. \& Curtis, P. A. (eds.). (2000). What works in child welfare? Washington DC: Child Welfare League of America Press.

Layzer, J. 1. \& Goodson, B. D. (2001). National evaluation of family support programs. Cambridge, MA: Abr Associates (htwp:/wwwabt assoc.com)

Lewis, L., Aguilar, Y. F, Armstrong, B., Biondi, C. O., Buck, M., Curry, P., McCroskey, J., Olenick, M., Perry, J., Riordan, N. D., Wainwright, M. \& Weinstein, V. (2000). From child welfare to child well-being. Pasadena, CA: Casey Family Program. 
Los Angeles County Children's Planning Council. (2004). 2004 Children's Scorecard. Health, fimilies and income: Key areas of child well-being for school readiness and success. Los Angeles, CA: author.

Marsenich, L. (2002). Evidence-based practices in mental health services for foster youth. Sacramento, CA: California Institute for Mental Health.

C. McAuley, D. Pecora \& W. Rose (eds.). (in press). Enhancing the well being of children and families through effective interventions: UK and USA evidence for practice. London \& Philadelphia: Jessica Kingsley Publishers.

McCroskey, J. (2003a). Child welfare: Controversies and possibilities. In F. Jacobs, D. Wertlieb, \& R. M. Lerner (eds.) Handbook of applied developmental science, Promoting positive child, adolescent and family development through resedrch, policies and programs, Vol. 2. Thousand Oaks, CA: Sage Publishers: 371-393.

McCroskey, J. (2003b). Walking the collabontion talk: Ten lessons learned from the Los Angeles County Children's Planning Council. Los Angeles, CA: Children's Planning Council.

McCroskey, J. (in press). Family-centered community-based supports, services and capacity-building: Effectiven ess and promising approaches. In C. McAuley, P. Pecora \& W. Rose (eds.). Enbancing the well being of children and families through effective interventions: UK and USA evidence for practice. London \& Philadelphia: Jessica Kingsley Publishers:

Munto, E. (2004). A simpler way to understand the results of risk assessment instruments, Children and youth services review, $26, \mathrm{pp} .873-883$.

National Research Council \& Institure of Medicine. (2000). From neurons to neighborhoods: The science of early childhood development. In J. P. Shonkoff \& D. A. Phillips (Eds.). Board on Children, Youth and Families, Commission on Behavioral and Social Sciences and Education. Washington DC: National Academy Press.

Needell, B. \& Patterson, K. (2004). The cbild welfare system improvement and accountability act (AB 636): Improving results for children and youth in California. A what works policy brief. Sacramento, $C A$ : Foundation Consorrium for California Children and Youth.

Osbourne, D. \& Plastrik, P. (1997). Banishing bureducracy, The five strategies for reinventing govern ment. NY: Plume, Penguin Putnam Inc.

Schorr, L. B. (1997). Common purpose, Strengthening families and neighborhoods to rabuild America. NY: Anchor Books, Random House.

Thomas, D., Leicht, C., Hughes, C., Madigan, A. \& Dowell, K.. (2002). Emerging practices in the prevention of child abuse and neglect. Washington DC: Office on Child Abuse and Neglect, US Department of Health and Human Services.

Tough, P. (2004). The Harlem project. New York Times Magazine, June 20, pp. 44-73.

Trickett, P. K. \& Schellenbach (eds.). (1998). Volente agdinst children in the family and the community. Washington DC: American Psychological Association.

U.S. Department of Health and Human Services. Administration for Children and Families/Chisdren's Bureau and Office of the Assistant Secretary for Planning and Evaluation (HHS/ACF \& OASPE). (2003). National study of child protective services systems and reform efforts: A stummary report. Washington DC: U. S. Government Printing Office.

U.S. Department of Health and Human Services, Administration for Children and Families, Child Welfare Reviews. Retrieved April 30, 2005. http:/wwwacf.hhs.gov/programs/cb/cwrp/index. hem

Waldfogel, J. (1998). The future of child protection, How to break the cycle of abuse and neglect. Cambridge, MA: Harvard University Press.

Walkowitz, D. J. (1999). Working with class: Social workers and the politics of middle-class identity. 
Chapel Hill, NC: University of Norh Carolina Press.

Wolfe, D, A. (1999). Child abuse: Implications for child development and psychopathology (2nd edition). Thousand Oaks, CA: Sage.

Zimmerman, F. (2003). Doing business differently, Changing policy and practice in the St. Louts Divim sion of Family Services. NY: Center for Community Partnerships in Child Welfare and Washington DC: Center for Study of Social Policy.

\section{Author's Note}

Address correspondence to Jacquelyn McCroskey, DSW, John Milner Associate Professor of Child Welfare, University of Southern California School of Social Work, Montgomery Ross Fisher Building, Los Angeles, CA 90089-0411. e-mail: mccroske@usc. edu 